\title{
The Role of MIF-173G/C Gene Polymorphism in the Susceptibility of Autoimmune Diseases
}

\author{
Xiangrong Du, ${ }^{1,2}$ Ruixia Li, ${ }^{1}$ Shoujun Song, ${ }^{3}$ Lei Ma $\mathbb{D}^{,},{ }^{4}$ and Haibo Xue $\mathbb{D}^{1}$ \\ ${ }^{1}$ Department of Endocrinology and Metabolism, Binzhou Medical University Hospital, 661 Second Huanghe Road, \\ Binzhou 256603, China \\ ${ }^{2}$ Department of Internal Medicine, Linzi District People's Hospital, No. 139 Huangong Road, Zibo 255400, China \\ ${ }^{3}$ Department of Endocrinology, Yantai Affiliated Hospital of Binzhou Medical University, No. 717 Jinfu Street, Yantai 264100, China \\ ${ }^{4}$ Department of Dermatology, Binzhou Medical University Hospital, No. 661 Second Huanghe Road, Binzhou 256603, China
}

Correspondence should be addressed to Lei Ma; doctor_malei@hotmail.com and Haibo Xue; xue_haibo@hotmail.com

Received 11 February 2020; Accepted 26 March 2020; Published 28 April 2020

Academic Editor: Yasumasa Kato

Copyright (C) 2020 Xiangrong Du et al. This is an open access article distributed under the Creative Commons Attribution License, which permits unrestricted use, distribution, and reproduction in any medium, provided the original work is properly cited.

\begin{abstract}
Some certain genetic polymorphisms have been considered to implicate in the pathogenesis and progression of autoimmune diseases and may predispose to an early stage of general autoimmune susceptibility. Recent studies have been conducted to investigate the association between macrophage migration inhibitory factor- (MIF-) 173G/C gene polymorphism and autoimmune diseases; however, the results were not exactly identical. In the present study, a systematic review and metaanalysis of case-control studies was performed to estimate the relationship. A comprehensive search of PubMed, Ebsco, EMbase, WanFang databases and CNKI was done. Odds ratio (ORs) and corresponding 95\% confidence intervals (CIs) were combined to pool the effect size. The publication bias was examined by Begg's funnel plots and Egger's test. RevMan 5.3 and STATA 12.0 software were used for statistical processing. 23 papers were included, and the results revealed that MIF-173G/C was significantly associated with an increased risk of autoimmune diseases in five genetic models (recessive genetic model: OR $=1.95$, 95\% CI: 1.52-2.50; dominant genetic model: OR = 1.35, 95\% CI: 1.24-1.46; allele model: OR = 1.32, 95\% CI: 1.23-1.41; homozygote model: $\mathrm{OR}=1.92,95 \%$ CI: 1.57-2.35; heterozygote model: $\mathrm{OR}=4.92,95 \%$ CI: 4.03-6.02), whether in Asia, Europe, or North America. Furthermore, subgroup analysis showed an increasing risk in rheumatoid arthritis (RA), ulcerative colitis (UC), Crohn's disease (CD), atopic dermatitis (AD), Henoch-Schonlein purpura (HSP), and Henoch-Schonlein purpura nephritis (HSPN), but it was not related to the susceptibility of autoimmune hepatitis (AIH). Therefore, it could be considered that MIF-173G/C polymorphism could increase the susceptibility of autoimmune diseases, while there may be the discrepancy of disease entity.
\end{abstract}

\section{Introduction}

Macrophage migration inhibitory factor (MIF) is a proinflammatory cytokine mainly released from Th2 cells and macrophages, which can mediate the host response to infection and stress by activating innate and adaptive immune pathways $[1,2]$. In humans, MIF is encoded by a single gene located on chromosome $22 \mathrm{q} 11.2 \mathrm{~m}$, a $12 \mathrm{kD}$ peptide comprising 114 amino acids [3]. It mainly interacts with its receptor CD74 to form a complex with CD44, which can result in the lasted activation of the ERK-MAPK pathway by a Src tyrosine kinase signal transduction. Downstream effects of this pathway include $\mathrm{NF} \kappa \mathrm{B}$ translocation to the nucleus, upregulation of PLA2 and prostaglandins, and stimulation of the arachidonic acid pathway [4]. So far, a single-nucleotide polymorphism in the 50 regions of the MIF gene, MIF$173 \mathrm{G} / \mathrm{C}$, a $\mathrm{G}$ to $\mathrm{C}$ transversion within the MIF promoter region at position -173 creates an AP4 transcription factor binding site $[5,6]$. Previous studies have shown that MIF$173 \mathrm{G} / \mathrm{C}$ polymorphism was related to the susceptibility of 
cancer [7], tuberculosis [8], and coronary atherosclerosis [9]. Recently, many studies have indicated that MIF-173G/C is associated with the pathogenesis and progression of autoimmune diseases.

The autoimmune diseases (AID) are characterized by dysfunction of the immune system leading to the loss of immune tolerance against self-tissues, the presence of autoreactive $\mathrm{T}$ and $\mathrm{B}$ cells, and a complex pathogenesis of multifactorial etiology, whereas genetic, epigenetic, and environmental factors are together responsible for the onset of AID $[10,11]$. So far, we have come to understand that certain genetic factors, including genetic polymorphisms implicated in autoimmune diseases, may predispose to an early stage of general autoimmune susceptibility [12]. It has been a new hot spot about the relationship between MIF-173G/C and autoimmune diseases. In Graves' disease (GD), MIF-173G/C plays a dual effect, which is not only a risk factor for the morbidity of goiter but also a protective role in the development of untreated severe goiter [13]. It was considered that MIF-173G/C might play an important role in the susceptibility of UC, but not in CD [14]. Due to the divergence of the researches, we resolved on devising a meta-analysis to evaluate the relationship between them.

\section{Materials and Methods}

2.1. Literature Research. A comprehensive document search was conducted in the PubMed, Ebsco, Embase, and Chinese WanFang databases and China National Knowledge Infrastructure (CNKI) in view of the relationship between MIF-173G/C and autoimmune diseases from the inception to October 10, 2019. The search strategy used in the present study was "macrophage migration inhibitory factor OR MIF" AND "polymorphism OR variant OR mutation" AND "rs755266" AND "Autoimmune disease OR autoimmune disorder OR AD OR AID." The language is restricted to English and Chinese, and the study manually retrieves references from the study and the latest review.

2.2. Eligibility Criteria. In the present meta-analysis, the included literatures must meet the flowing criteria: (1) case-control study or cohort study was published publicly; (2) the study must assess the association of MIF-173G/C gene polymorphism with the susceptibility of autoimmune diseases; (3) the experimental and control subjects involved in studies are human being; and (4) the odds ratios (ORs) and 95\% confidence intervals (95\% CIs) could be calculated by sufficient genotypic frequencies available in the studies. We applied the Preferred Reporting Items for Systematic Review and Meta-analysis statement (PRIMSA) for the meta-analysis.

2.3. Exclusion Criteria. We excluded the relevant documents according to the following standards: (1) duplicate publications, reviews, meta-analysis, letters, and editorial comments; (2) non-case-control study; (3) animal experiment; and (4) failure to offer the genotypic or allelic frequencies.
2.4. Data Extraction. Two investigators selected literatures independently by checking the title, abstract, and full text based on the eligibility and excluded criteria and ironed out the differences by discussing. And then the following contents were extracted: first author's name, year of publication, country of origin, disease species, genotyping method, the total number of controls and cases, the genotypic and allelic frequencies in controls and cases, and Hardy-Weinberg equilibrium (HWE) test results in controls.

The quality evaluation of literature involved in the present meta-analysis also was done by two investigators in the light of Newcastle-Ottawa Scale (NOS) [15]. We evaluated the quality from the following three aspects: subject selection, comparability of subjects, and clinical outcomes. The aggregate score is 9 points, and the research of high quality is more than 6 points.

2.5. Statistical Analysis. In the present study, HWE was used to evaluate the controls of all the included literatures by the chi-square test, and $P>0.05$ was considered the genetic balance in the population. The pooled odds ratio (ORs) and corresponding 95\% confidence intervals (CIs) were calculated to estimate the strength of the association between MIF-173G/C and autoimmune diseases in the following five genetic models: recessive genetic model (CC vs. $\mathrm{GC}+\mathrm{GG}$ ), dominant genetic model (CC+GC vs. GG), allelic genetic model ( $C$ vs. $G$ ), heterozygous genetic model (GC vs. GG), and homozygous genetic model (CC vs. GG). The conspicuous level of statistic was assessed by a $Z$-test with $P<0.05$. The heterogeneity was assessed by Cochran's $Q$ statistic and $I$-squared $\left(I^{2}\right)$ metric. The random effects model was selected when there is statistical heterogeneity with $P<0.10$ or $I^{2}>50 \%$. Otherwise, the fixed effects model is used for the merger analysis. We sequentially eliminated the single document to estimate the sensitivity by screening the OR and heterogeneity. Otherwise, subgroup analyses were performed by disease and area (Asian, Europe, and North America). Potential publication bias was assessed by Begg's funnel plots and Egger's test, and $P<0.05$ was considered when there was significantly statistical publication bias. The calculation of ORs, 95\% CI, heterogeneity, and sensitivity analysis was conducted by using the software Review manager (RevMan, version 5.3, Cochrane Collaboration, Copenhagen, Denmark). The subgroup analysis, Begg's funnel plots, and Egger's test were performed by the STATA 12.0 software (STATA Corp LP, College Station, USA).

\section{Results}

3.1. Characteristics of Eligible Studies. In the initial search from PubMed, Ebsco, Embase, and Wanfang databases and CNKI, 215 potential records were identified based on our search strategy. All the retrieved research articles were screened manually by examining abstracts and texts; meanwhile, 192 publications were excluded in accordance to the exclusion criteria. Finally, 23 literatures [2, 14, 16-36] were included in the present meta-analysis. Figure 1 shows the 


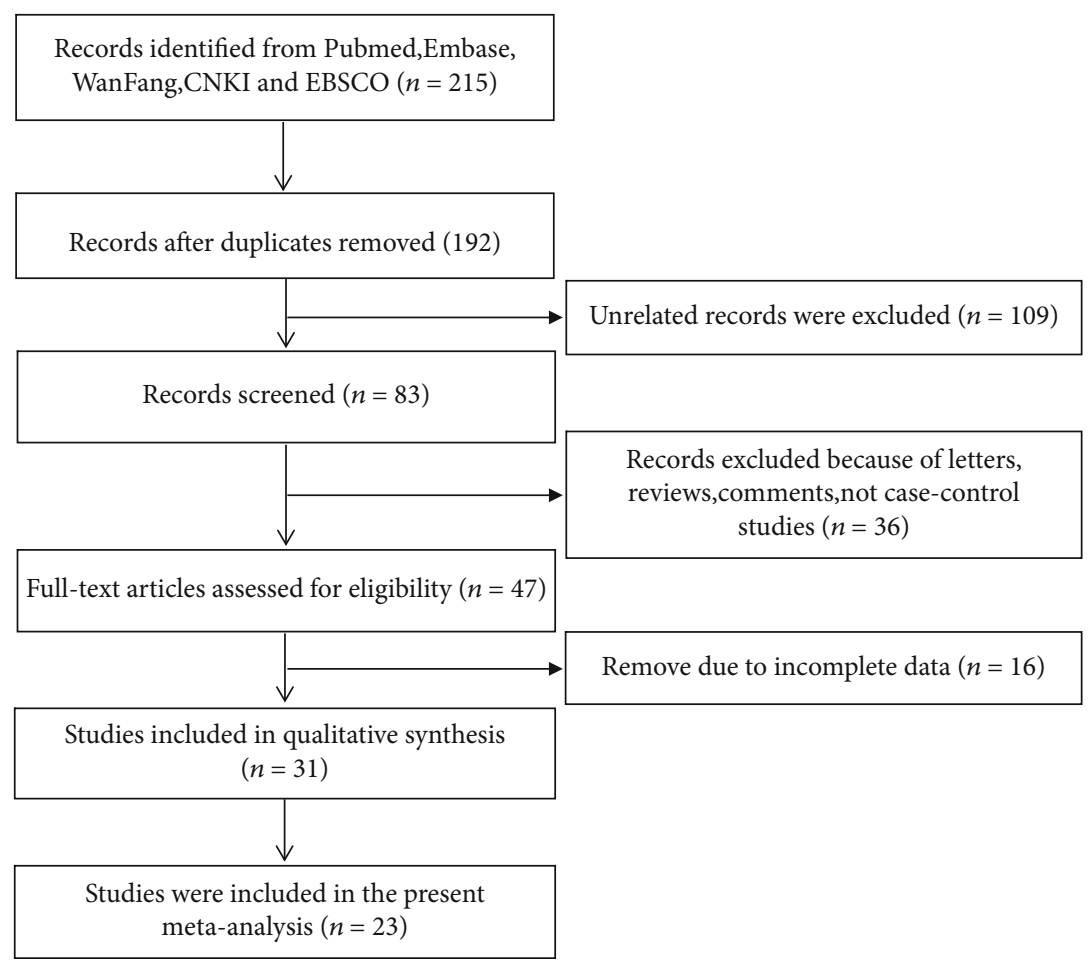

FIgURE 1: PRISMA flow diagram for the inclusion of studies in the meta-analysis.

selection procedure: a total of twenty-nine human casecontrol trials were adopted, containing five databases of them which evaluated the relationship between MIF-173G/C and rheumatoid arthritis (RA) [16-20]. Three databases were Crohn's disease (CD) $[14,21,22]$, ulcerative colitis (UC) $[14,22,23]$, and autoimmune hepatitis (AIH) $[2,24]$, respectively. Two databases were about atopic dermatitis (AD) $[25,26]$, Henoch-Schonlein purpura nephritis (HSPN) [27], and Henoch-Schonlein purpura (HSP) [28]. The other nine diseases were inquired in single databases, including ankylosing spondylitis (AS) [29], primary gout [30], primary biliary cirrhosis (PBC) [24], psoriasis (Ps) [31], systemic lupus erythematosus (SLE) [32], Vogt-Koyanagi-Harada syndrome (VKH) [33], adult still disease (AOSD) [34], Behcet's disease (BD) [35], and scleroderma (SD) [36]. The areas of the studies involved in the present analysis were Asian, Europe, and North America. The genotyping method included the Polymerase Chain Reaction-Restriction Fragment Length Polymorphism (PCR-RFLP), PCR, and ELISA. All people frequencies of the controls were in HWE $(P>0.05)$. The quality scores of the involved studies were evaluated according to NOS, and all scores were more than 6 points. The analysis was conducted only when more than two articles were included in each subgroup. The characteristics of the involved studies are revealed in Table 1.

3.2. Results of Meta-analysis. 5559 cases and 7335 controls were involved in the ultima meta-analysis. There was no significant heterogeneity between the MIF-173G/C polymorphism and autoimmune diseases (both $P>0.1$ ), so the fixed effects model was used for meta-analysis. The polled sum- mary crude odds radios (ORs) and corresponding 95\% confidence intervals (CIs) in all genetic models were as follows: recessive genetic model (CC vs. GC+GG): $\mathrm{OR}=1.95,95 \%$ CIs $=1.52-2.50, P<0.05$; dominant genetic model $(\mathrm{CC}+\mathrm{GC}$ vs. $\mathrm{GG}): \mathrm{OR}=1.35,95 \% \mathrm{CIs}=1.24-1.46, P<0.05$; allelic genetic model ( $\mathrm{C}$ vs. $\mathrm{G})$ : $\mathrm{OR}=1.32,95 \% \mathrm{CIs}=1.23-1.41$, $P<0.05$; heterozygous genetic model (GC vs. GG): $\mathrm{OR}=$ $4.92,95 \% \mathrm{CIs}=4.03-6.02, P<0.05$; and homozygous genetic model (CC vs. GG): $\mathrm{OR}=1.92,95 \% \mathrm{CIs}=1.57-2.35, P<0.05$. The results are shown in Table 2 and Figures 2-6.

In addition, the results of the subgroup analysis performed according to area revealed the following data: in Asia, recessive genetic model ( $(\mathrm{CC}$ vs. $\mathrm{GC}+\mathrm{GG})$ : $\mathrm{OR}=$ $2.32,95 \% \mathrm{CIs}=1.79-3.00, \quad P<0.05)$, dominant genetic model $((\mathrm{CC}+\mathrm{GC}$ vs. GG): $\mathrm{OR}=1.38,95 \% \mathrm{CIs}=1.23-1.53$, $P<0.05)$, allelic genetic model $((\mathrm{C}$ vs. $\mathrm{G}): \mathrm{OR}=1.40,95 \%$ CIs $=1.28-1.54, \quad P<0.05)$, heterozygous genetic model ((GC vs. GG): $\mathrm{OR}=1.29,95 \% \mathrm{CIs}=1.15-1.44, P<0.05)$, and homozygous genetic model ((CC vs. GG): $\mathrm{OR}=1.91$, 95\% CIs $=1.55-2.38, P<0.05)$; in Europe, recessive genetic model ((CC vs. GC+GG): $\mathrm{OR}=1.58,95 \% \mathrm{CIs}=1.09-2.29$, $P<0.05)$, dominant genetic model $((\mathrm{CC}+\mathrm{GC}$ vs. GG): $\mathrm{OR}=1.20,95 \% \mathrm{CIs}=1.03-1.39, P<0.05)$, allelic genetic model ( $(\mathrm{C}$ vs. $\mathrm{G}): \mathrm{OR}=1.21,95 \% \mathrm{CIs}=1.06-1.37, P<0.05)$, heterozygous genetic model ((GC vs. GG): $\mathrm{OR}=1.51,95 \%$ CIs $=0.99-1.35, P=0.70$ ), and homozygous genetic model ((CC vs. GG): $\mathrm{OR}=1.56,95 \% \mathrm{CIs}=1.10-2.21, P<0.05)$; in North America, recessive genetic model ((CC vs. GC+GG): $\mathrm{OR}=1.21,95 \% \mathrm{CIs}=0.73-2.00, P=0.45)$, dominant genetic model $((\mathrm{CC}+\mathrm{GC}$ vs. $\mathrm{GG}): \mathrm{OR}=1.38,95 \% \mathrm{CIs}=1.16-1.63$, $P<0.05)$, allelic genetic model $((\mathrm{C}$ vs. $\mathrm{G}): \mathrm{OR}=1.28,95 \%$ 
TABLE 1: Characteristics of the included studies.

\begin{tabular}{|c|c|c|c|c|c|c|c|c|c|c|c|c|}
\hline \multirow{2}{*}{ First author } & \multirow{2}{*}{ Year } & \multirow{2}{*}{ Disease } & \multirow{2}{*}{ Country } & \multirow{2}{*}{ Area } & \multirow{2}{*}{ Method } & \multicolumn{3}{|c|}{ Case } & \multicolumn{3}{|c|}{ Control } & \multirow{2}{*}{$P_{\mathrm{HWE}}$} \\
\hline & & & & & & GG & GC & $\mathrm{CC}$ & GG & GC & $\mathrm{CC}$ & \\
\hline Alfonso & 2007 & RA & Mexico & North America & PCR-RFLP & 431 & 157 & 18 & 681 & 188 & 18 & 0.24 \\
\hline Assis (1) & 2014 & $\mathrm{AIH}$ & America & Europe & ELISA & 31 & 13 & 1 & 219 & 63 & 4 & 0.83 \\
\hline Assis (2) & 2014 & $\mathrm{PBC}$ & America & Europe & ELISA & 215 & 82 & 7 & 219 & 63 & 4 & 0.83 \\
\hline Fei (1) & 2008 & UC & China & Asia & PCR-RFLP & 44 & 27 & 13 & 79 & 55 & 8 & 0.7 \\
\hline Fei (2) & 2008 & $\mathrm{CD}$ & China & Asia & PCR-RFLP & 8 & 5 & 2 & 79 & 55 & 8 & 0.7 \\
\hline Nunez & 2007 & $\mathrm{CD}$ & Spain & Europe & NA & 372 & 149 & 10 & 681 & 188 & 18 & 0.24 \\
\hline Çevik & 2016 & AS & Turkey & Europe & RFLP & 116 & 42 & 3 & 136 & 49 & 9 & 0.11 \\
\hline Zhan & 2013 & VKH & China & Asia & PCR-RFLP & 360 & 226 & 14 & 417 & 167 & 16 & 0.88 \\
\hline David (1) & 2016 & $\mathrm{AIH}$ & Japan & Asia & ELISA & 36 & 14 & 2 & 18 & 12 & 0 & 0.17 \\
\hline David (2) & 2016 & $\mathrm{AIH}$ & America & Europe & ELISA & 37 & 15 & 1 & 18 & 12 & 0 & 0.17 \\
\hline Sanchez & 2006 & SLE & Spain & Europe & PCR-RFLP & 503 & 175 & 33 & 570 & 171 & 14 & 0.78 \\
\hline Wang & 2013 & AOSD & China & Asia & PCR-RFLP & 69 & 26 & 5 & 157 & 42 & 1 & 0.31 \\
\hline $\mathrm{Wu}$ & 2009 & Ps & China & Asia & PCR-RFLP & 137 & 94 & 9 & 163 & 95 & 8 & 0.8 \\
\hline Jung & 2016 & $\mathrm{AD}$ & Korea & Asian & PCR-RFLP & 117 & 51 & 10 & 61 & 18 & 1 & 0.18 \\
\hline Karolina (1) & 2011 & UC & Poland & Europe & PCR-RFLP & 38 & 19 & 1 & 99 & 23 & 1 & 0.79 \\
\hline Karolina (2) & 2011 & $\mathrm{CD}$ & Poland & Europe & PCR-RFLP & 28 & 12 & 1 & 99 & 23 & 1 & 0.79 \\
\hline Larissa & 2006 & RA & Germany & Europe & PCR & 90 & 24 & 5 & 160 & 59 & 6 & 0.84 \\
\hline $\mathrm{Ma}$ & 2013 & $\mathrm{AD}$ & China & Asia & NA & 93 & 65 & 15 & 136 & 75 & 7 & 0.39 \\
\hline M.A. & 2013 & RA & Mexico & North America & PCR-RFLP & 43 & 49 & 8 & 53 & 42 & 5 & 0.36 \\
\hline $\mathrm{Wu}$ & 2006 & $\mathrm{SD}$ & America & Europe & ELISA & 105 & 47 & 7 & 149 & 72 & 6 & 0.44 \\
\hline Timothy & 2005 & RA & Holland & Europe & PCR & 188 & 71 & 11 & 198 & 69 & 10 & 0.20 \\
\hline Zheng & 2012 & $\mathrm{BD}$ & China & Asia & PCR-RFLP & 359 & 212 & 29 & 417 & 167 & 16 & 0.88 \\
\hline Hao (1) & 2015 & HSPN & China & Asia & PCR-RFLP & 3 & 8 & 20 & 8 & 15 & 7 & 1.00 \\
\hline Hao (2) & 2015 & HSPN & China & Asia & PCR-RFLP & 5 & 11 & 24 & 10 & 14 & 6 & 0.79 \\
\hline Ruan & 2014 & UC & China & Asia & NA & 99 & 61 & 5 & 124 & 69 & 6 & 0.33 \\
\hline Xie & 2007 & RA & China & Asia & PCR & 28 & 10 & 5 & 19 & 8 & 3 & 0.16 \\
\hline Zhang (1) & 2014 & HSP & China & Asia & PCR-RFLP & 2 & 7 & 16 & 5 & 13 & 7 & 0.82 \\
\hline Zhang (2) & 2014 & HSP & China & Asia & PCR-RFLP & 2 & 8 & 15 & 10 & 14 & 6 & 0.79 \\
\hline Zhuang & 2014 & PG & China & Asia & PCR-RFLP & 18 & 9 & 3 & 190 & 114 & 9 & 0.09 \\
\hline
\end{tabular}

RA: rheumatoid arthritis; AIH: autoimmune hepatitis; PBC: primary biliary cirrhosis; UC: ulcerative colitis; CD: Crohn's disease; AS: ankylosing spondylitis; VKH: Vogt-Koyanagi-Harada syndrome; SLE: systemic lupus erythematosus; AOSD: adult Still disease; Ps: psoriasis; AD: atopic dermatitis; SD: scleroderma; BD: Behcet's disease; HSPN: Henoch-Schonlein purpura nephritis; HSP: Henoch-Schonlein purpura; PG: primary gout; PCR-RFLP: Polymerase Chain Reaction-Restriction Fragment Length Polymorphism; PCR: Polymerase Chain Reaction; NA: not available.

TABLE 2: The summary of the results from different comparative genetic models in all subjects.

\begin{tabular}{|c|c|c|c|c|c|c|c|c|c|c|}
\hline Genetic models & $I^{2}(\%)$ & $P_{\mathrm{I}}$ & Effects model & OR $(95 \% \mathrm{CI})$ & $Z$ & $P_{\mathrm{z}}$ & $\begin{array}{c}\text { Egger's regression } \\
\text { analysis }\end{array}$ & $P_{\mathrm{E}}$ & $\begin{array}{c}\text { Begg's regression } \\
\text { analysis }\end{array}$ & $P_{\mathrm{B}}$ \\
\hline $\mathrm{C} / \mathrm{G}$ & 37 & 0.03 & FIX & $1.32(1.23,1.41)$ & 8.13 & 0.01 & 0.14 & 0.89 & 0.36 & 0.72 \\
\hline $\mathrm{CC} / \mathrm{GG}$ & 19 & 0.18 & FIX & $1.92(1.57,2.35)$ & 6.40 & 0.01 & 0.80 & 0.43 & 1.41 & 0.16 \\
\hline GC/GG & 0 & 0.62 & FIX & $4.92(4.03,6.02)$ & 15.51 & 0.01 & -1.89 & 0.07 & 1.07 & 0.29 \\
\hline $\mathrm{CC}+\mathrm{GC} / \mathrm{GG}$ & 1 & 0.45 & FIX & $1.35(1.24,1.46)$ & 7.42 & 0.01 & 0.21 & 0.83 & 0.92 & 0.36 \\
\hline $\mathrm{CC} / \mathrm{GC}+\mathrm{GG}$ & 27 & 0.09 & FIX & $1.95(1.52,2.50)$ & 5.28 & 0.01 & 1.04 & 0.31 & 0.73 & 0.46 \\
\hline
\end{tabular}

CIs $=1.10-1.48, P<0.05)$, heterozygous genetic model $((\mathrm{GC}$ vs. $\mathrm{GG}): \mathrm{OR}=1.38,95 \% \mathrm{CIs}=1.16-1.65, P<0.05)$, and homozygous genetic model ((CC vs. GG): $\mathrm{OR}=1.30,95 \%$ CIs $=0.80-2.12, P=0.29)$. The results are shown in Table 3 .
In the analysis stratified by diseases, the results demonstrated the following: in $\mathrm{AD}$, recessive genetic model (CC vs. $\mathrm{GC}+\mathrm{GG})$ : $\mathrm{OR}=3.03,95 \% \mathrm{CIs}=1.34-6.83, \quad P<0.05$; dominant genetic model $(\mathrm{CC}+\mathrm{GC}$ vs. $\mathrm{GG}): \mathrm{OR}=1.29$, 


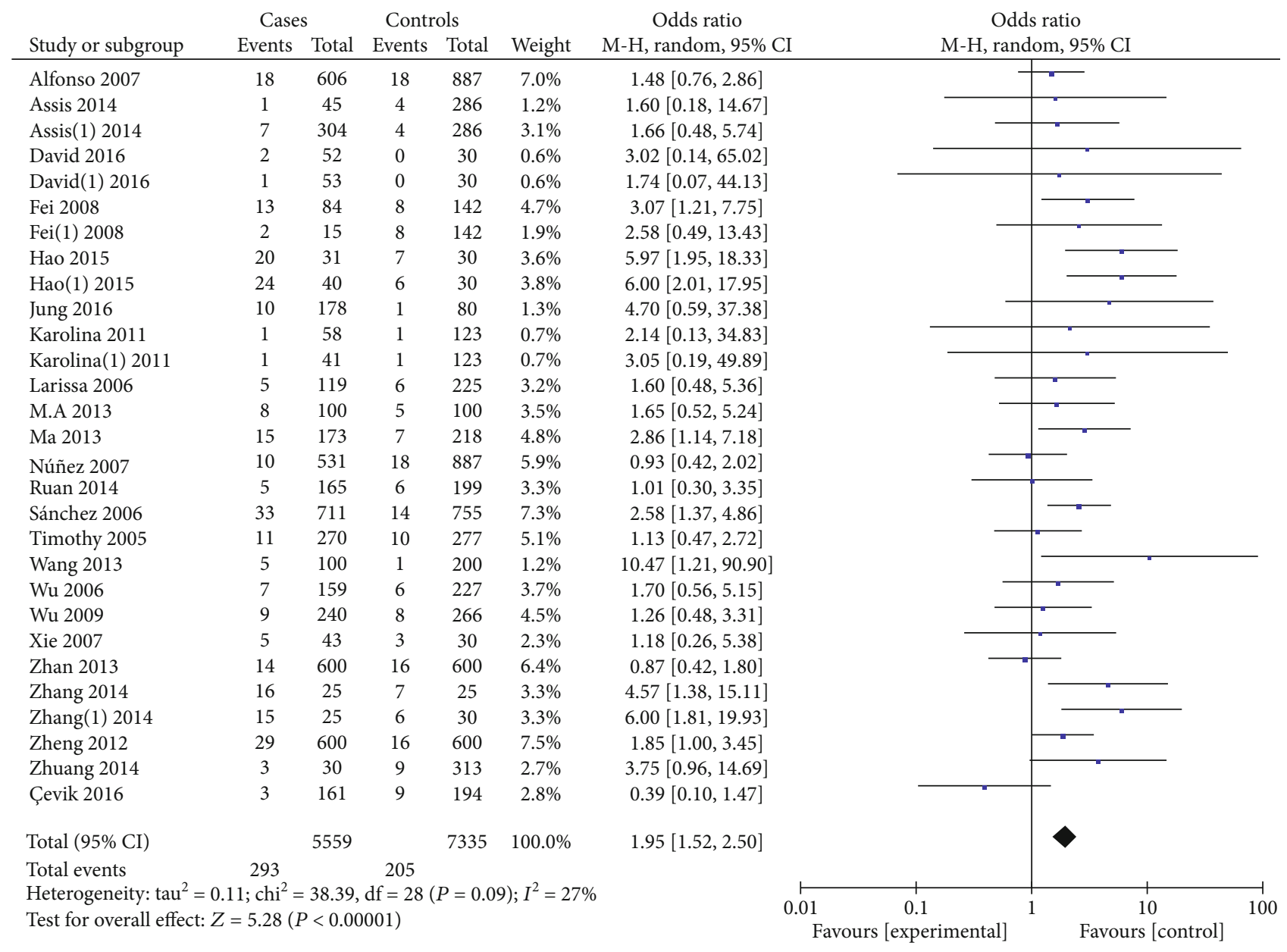

Figure 2: Association between MIF-173G/C gene polymorphism and autoimmune diseases in recessive model (CC/GC+GG).

95\% CIs $=1.04-1.59, P<0.05$; allelic genetic model $(\mathrm{C}$ vs. $\mathrm{G}): \mathrm{OR}=1.41,95 \% \mathrm{CIs}=1.13-1.76, P<0.05$; homozygous genetic model (CC vs. GG): $\mathrm{OR}=3.21,95 \% \mathrm{CIs}=1.44$ -7.18, $P<0.05$; and heterozygous genetic model (GC vs. GG) had no statistical significance. In RA, dominant genetic model $(\mathrm{CC}+\mathrm{GC}$ vs. $\mathrm{GG}): \mathrm{OR}=1.20,95 \% \mathrm{CIs}=$ 1.01-1.43, $P<0.05$; allelic genetic model (C vs. G): OR = $1.16,95 \% \quad \mathrm{CIs}=1.03-1.31, \quad P<0.05 ; \quad$ recessive genetic model (CC vs. GC+GG); heterozygous genetic model (GC vs. GG); and homozygous genetic model (CC vs. GG) had no statistical significance. In UC, recessive genetic model (CC vs. GC+GG): $\mathrm{OR}=1.93,95 \%$ CIs $=$ 1.01-3.01, $P<0.05$; allelic genetic model (C vs. G): OR = $1.22,95 \% \mathrm{CIs}=1.00-1.47, \quad P<0.05$; dominant genetic model (CC+GC vs. GG); heterozygous genetic model (GC vs. GG); and homozygous genetic model (CC vs. GG) had no statistical significance. In $\mathrm{CD}$, dominant genetic model $(\mathrm{CC}+\mathrm{GC}$ vs. GG): $\mathrm{OR}=1.30,95 \% \mathrm{CI}=$ 1.10-1.52, $P<0.05$; heterozygous genetic model (GC vs. GG): $\quad \mathrm{OR}=1.32, \quad 95 \% \quad$ CIs $=1.11-1.57, \quad P<0.05 ; \quad$ allelic genetic model ( $\mathrm{C}$ vs. $\mathrm{G})$ : $\mathrm{OR}=1.23,95 \% \mathrm{CIs}=1.04-1.47$, $P<0.05$; homozygous genetic model (CC vs. GG); and recessive genetic model ( $\mathrm{CC}$ vs. $\mathrm{GC}+\mathrm{GG}$ ) had no statistical significance. In HSP, recessive genetic model (CC vs. GC
$+\mathrm{GG}): \mathrm{OR}=2.60$, 95\% CIs $=1.55-4.37, P<0.05$; dominant genetic model $(\mathrm{CC}+\mathrm{GC}$ vs. $\mathrm{GG}): \mathrm{OR}=1.26,95 \% \mathrm{CIs}=$ 1.05-1.51, $P<0.05$; allelic genetic model ( $\mathrm{C}$ vs. $\mathrm{G}): \mathrm{OR}=$ 1.59, 95\% CIs $=1.28-1.98, P<0.05$; homozygous genetic model (CC vs. GG): $\mathrm{OR}=1.88,95 \% \mathrm{CIs}=1.25-2.82, P<0.05$; and heterozygous genetic model (GC vs. GG) had no statistical significance. In HPSN, recessive genetic model (CC vs. $\mathrm{GC}+\mathrm{GG})$ : $\mathrm{OR}=2.88,95 \% \mathrm{CIs}=1.72-4.83, P<0.05$; dominant genetic model (CC+GC vs. GG): $\mathrm{OR}=1.27,95 \% \mathrm{CI}$ $=1.06-1.53, P<0.05$; allelic genetic model ( $\mathrm{C}$ vs. $\mathrm{G}): \mathrm{OR}=$ 1.65, 95\% CIs $=1.33-2.05, P<0.05$; homozygous genetic model (CC vs. GG): $\mathrm{OR}=2.03,95 \% \mathrm{CIs}=1.32-3.12, P<$ 0.05; and heterozygous genetic model (GC vs. GG) had no statistical significance. And there was no significant association between the $\mathrm{AIH}$ and MIF-173G/C gene polymorphisms. The results are shown in Table 4.

3.3. Sensitivity Analysis. After eliminating any research, the total effect of meta-analysis did not change significantly, indicating that the results were stable and credible.

3.4. Publication Bias. As shown in Tables 2-4, Egger's and Begg's tests were conducted to detect the publication bias in the present meta-analysis. Whether in the total analysis 


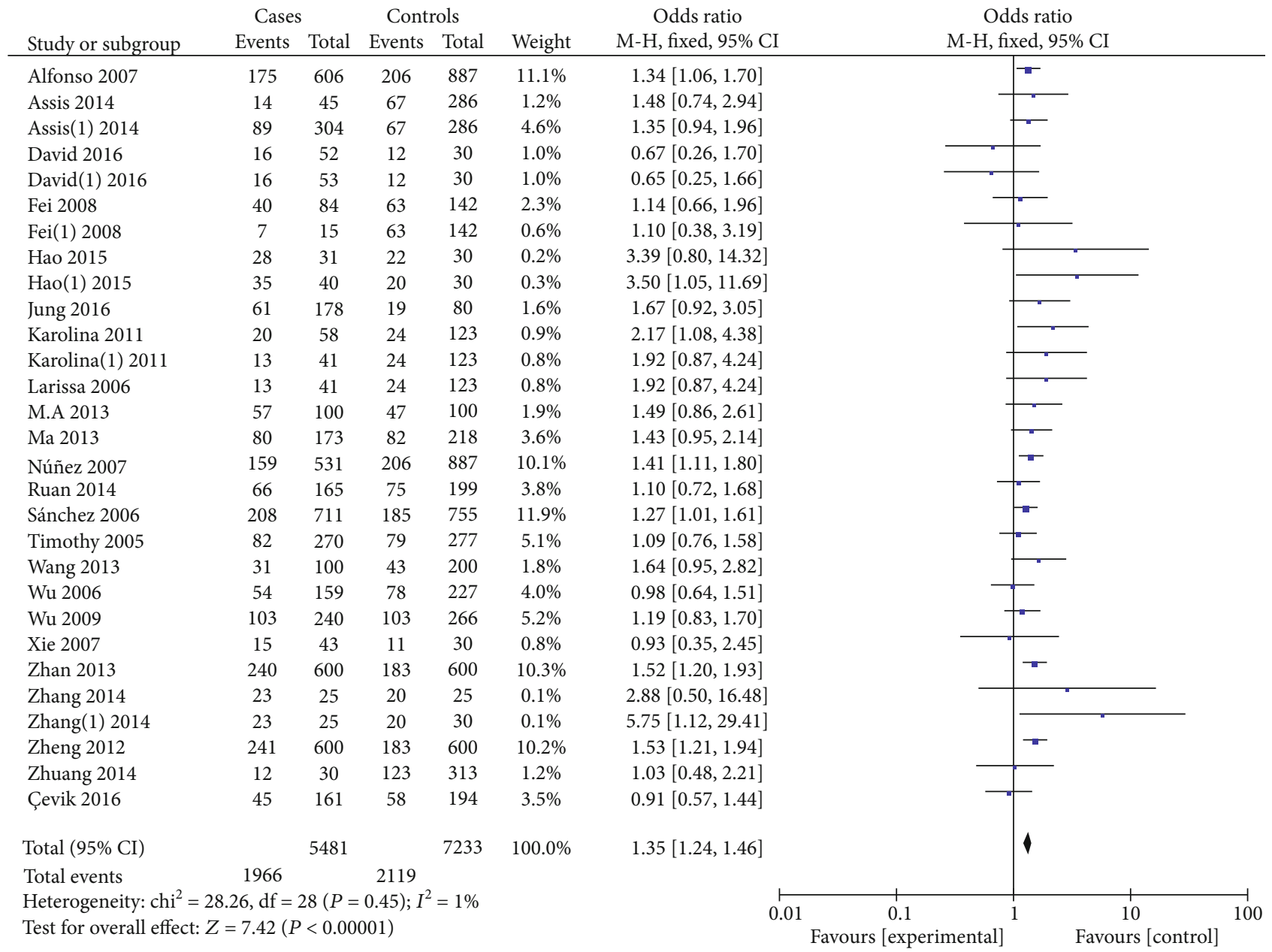

FIGURe 3: Association between MIF-173G/C gene polymorphism and autoimmune diseases in dominant model (CC+GC vs. GG).

or in the subgroup of area and disease, the $P$ values of Egger's and Begg's tests were all greater than 0.05, which demonstrated that the present study had no publication bias.

\section{Discussion and Conclusion}

MIF is an immunoregulatory cytokine secreted from various types of cells in different tissues, which can promote leukocyte recruitment and subsequently promote the expression and function of multiple cytokines and chemokines, including tumor necrosis factor (TNF), interleukin-6 (IL-6), CXCL1, and CCL2 [37]. Recently, MIF has been reported to be a key response regulator which can directly activate immune cells or participate in activation pathways initially triggered by other factors [38]. A functional singlenucleotide polymorphism (SNP) was identified in the untranslated $5^{\prime}$ region of MIF gene at position - 173 consisting of a $\mathrm{G}$ to $\mathrm{C}$ transition [39]. The new research about the variate action of MIF-173G/C in different diseases was conducted and revealed that MIF-173G/C polymorphism could weakly mediate the development of metabolic syndrome and significantly predict the risk of death by inducing low- grade inflammation independently in Turkish man, but not in woman [40]. Furthermore, the carriage of MIF-173C was associated with unfavorable outcome and death in pneumococcal meningitis, demonstrating strongly that MIF alleles were a genetic marker of morbidity and mortality of pneumococcal meningitis [41].

At present, more and more researchers pay more attention to the roles of MIF-173G/C in autoimmune diseases. The level of MIF-173G/C in progressive multiple sclerosis (MS) is significantly increased in male, suggesting that it can be a sex-specific disease modifier and its receptor CD74 signaling might provide an effective, trackable therapeutic approach for MS subjects of two sexes [42]. In systemic lupus erythematosus (SLE), MIF-173C genotype may be a protective factor. However, the high expression of MIF polymorphisms is associated with an increased incidence of end-organ injury in Caucasians and African Americans [43]. And another study reported that MIF-173CC allele might increase the risk for RA, especially among CRP-negative patients in China [44]. In order to systematically elucidate the relationship between MIF-173G/C and autoimmune diseases, we designed the present meta-analysis. 


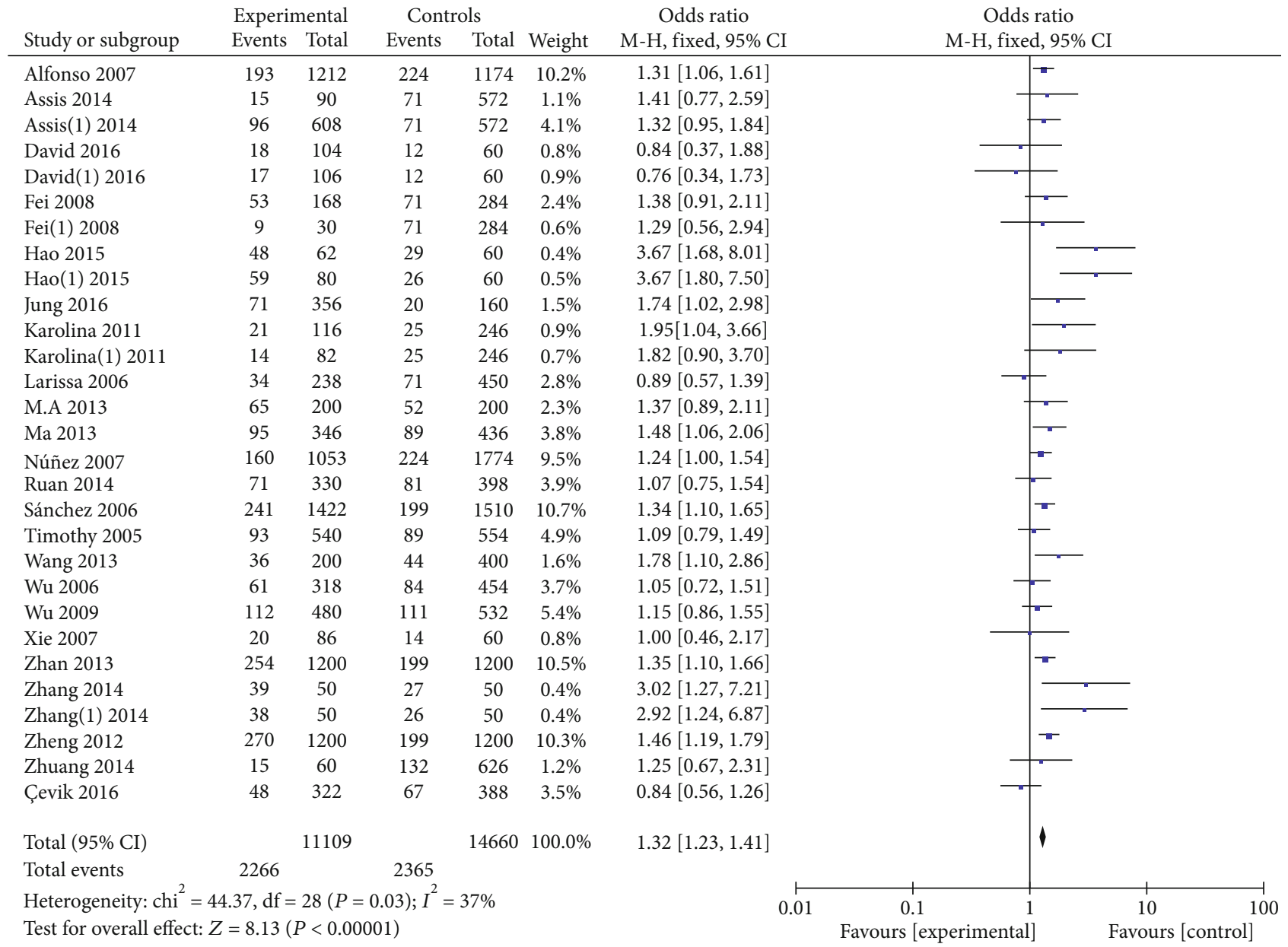

FIgUre 4: Association between MIF-173G/C gene polymorphism and autoimmune diseases in allelic model (C/G).

All the 23 articles were brought into the present meta-analysis, including 18 papers written in English and 5 papers written in Chinese $[20,23,27,28,30]$. Two of the Chinese literatures [20,23] are dissertations with high quality. The total results revealed that a strong correlation with pathogenesis of autoimmune disease, whether in the recessive genetic model $(\mathrm{OR}=1.95,95 \%$ $\mathrm{CI}=1.52$ to 2.50$)$, dominant genetic model $(\mathrm{OR}=1.35$, $95 \% \mathrm{CI}=1.24$ to 1.46$)$, allelic genetic model $(\mathrm{OR}=1.32$, $95 \% \mathrm{CI}=1.23$ to 1.41 ), heterozygous genetic model $(\mathrm{OR}=4.92,95 \% \mathrm{CI}=4.03$ to 6.02$)$, or homozygous genetic model $(\mathrm{OR}=1.92,95 \% \mathrm{CI}=1.57$ to 2.35$)$. When the MIF-173 GG genotypes were used as the reference group, the GC heterozygous genotype was associated with a significant 4.92 -fold increasing susceptibility to autoimmune diseases, particularly in the heterozygous model. Therefore, these data indicated that MIF-173G/C could significantly increase the susceptibility of autoimmune diseases, especially the MIF-173GC genotype.

The subgroups categorized by area demonstrated significant associations between MIF-173G/C and autoimmune diseases in Asia, Europe, and North America. In Asia, a strong pooled OR was detected in the recessive model $(\mathrm{OR}=2.32,95 \% \mathrm{CI}=1.79$ to 3.00$)$, dominant model $(\mathrm{OR}=1.38,95 \% \mathrm{CI}=1.23$ to 1.53$)$, allelic model $(\mathrm{OR}=1.40,95 \% \mathrm{CI}=1.28$ to 1.54$)$, heterozygous model $(\mathrm{OR}=1.29,95 \% \mathrm{CI}=1.15$ to 1.44$)$, or homozygous model $(\mathrm{OR}=1.91,95 \% \mathrm{CI}=1.55$ to 2.38$)$. Nevertheless, only 4 genetic models including the recessive model $(\mathrm{OR}=1.20$, $95 \% \mathrm{CI}=1.03$ to 1.39$)$, dominant model $(\mathrm{OR}=1.58$, $95 \% \mathrm{CI}=1.09$ to 2.29$)$, allelic model $(\mathrm{OR}=1.21,95 \%$ $\mathrm{CI}=1.06$ to 1.37$)$, and homozygous model $(\mathrm{OR}=1.56$, $95 \% \mathrm{CI}=1.10$ to 2.21 ) had statistical significance in Europe. In North America, the dominant model $(\mathrm{OR}=1.38,95 \% \mathrm{CI}=1.16$ to 1.63$)$, allelic genetic model $(\mathrm{OR}=1.28,95 \% \mathrm{CI}=1.10$ to 1.48$)$, heterozygous genetic model ( $\mathrm{OR}=1.38,95 \% \mathrm{CI}=1.16$ to 1.65$)$, and homozygous genetic model $(\mathrm{OR}=1.92,95 \% \mathrm{CI}=1.57$ to 2.35$)$ showed statistical significance. The abovementioned results indicated that the high expression of MIF-173G/C could increase the prevalence of autoimmune diseases whether in Asia, Europe, or North America. Additionally, the association was detected in all 5 genetic models especially in Asia, which revealed that MIF-173G/C could increase the susceptibility of autoimmune diseases more significantly compared with that in Europe and North America. Therefore, it can be considered that there may be regional differences. 


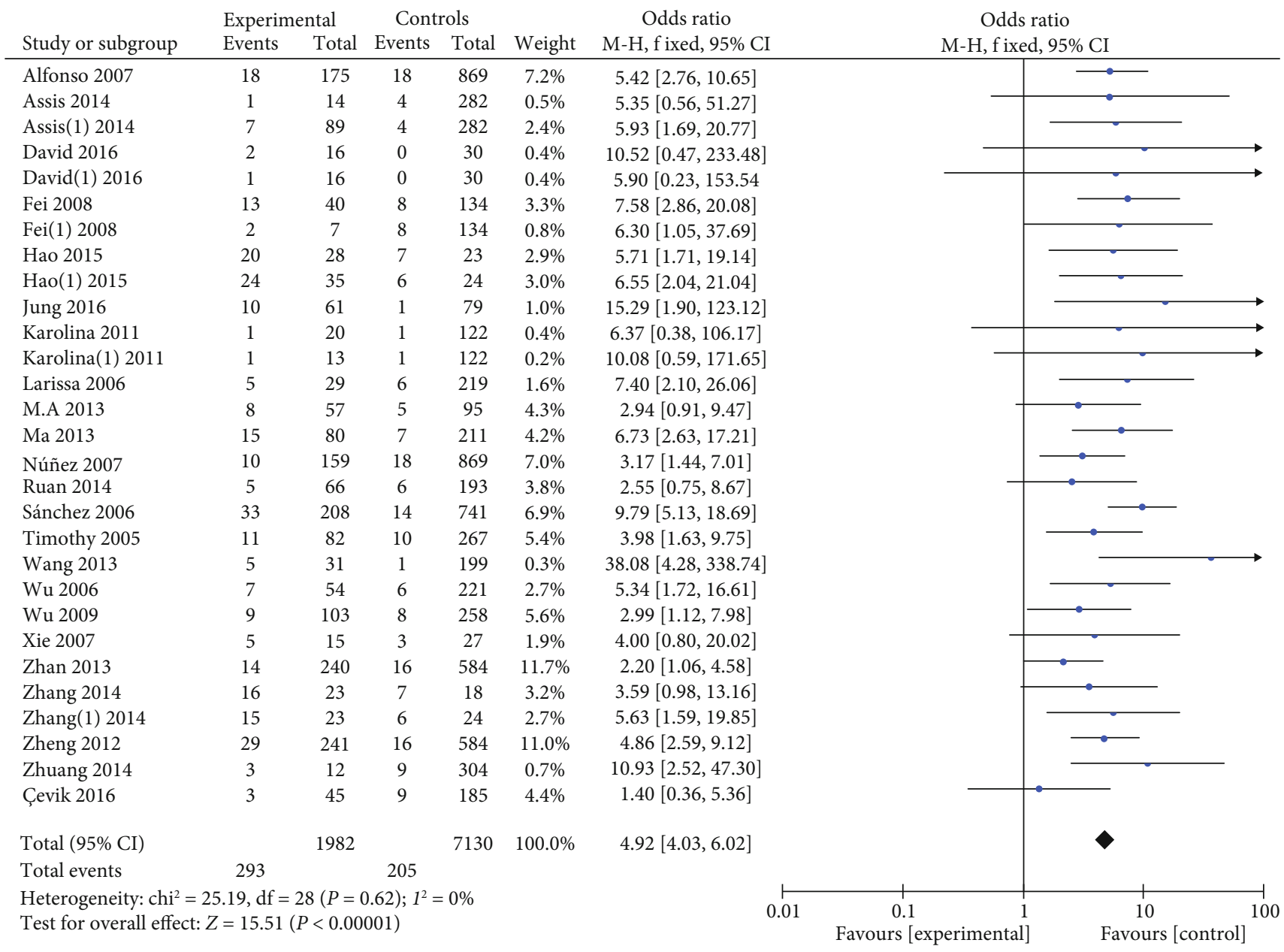

FIGURE 5: Association between MIF-173G/C gene polymorphism and autoimmune diseases in heterozygous model (GC/GG).

Moreover, it was found that MIF-173G/C was associated with the increased risk of RA in two genetic models including the recessive model $(\mathrm{OR}=1.20,95 \% \mathrm{CI}=1.01$ to 1.43$)$ and allelic model $(\mathrm{OR}=1.16,95 \% \mathrm{CI}=1.03$ to 1.31). In $\mathrm{UC}$, the allelic model $(\mathrm{OR}=1.22,95 \% \mathrm{CI}=$ 1.00 to 1.47$)$ and dominant model $(\mathrm{OR}=1.93,95 \% \mathrm{CI}$ $=1.01$ to 3.01 ) showed significant association, respectively. Three genetic models including the dominant model $(\mathrm{OR}=1.30,95 \% \mathrm{CI}=1.10$ to 1.52$)$, allelic model $(\mathrm{OR}=1.23,95 \% \mathrm{CI}=1.04$ to 1.47$)$, and heterozygous model $(\mathrm{OR}=1.32,95 \% \mathrm{CI}=1.11$ to 1.57$)$ had been demonstrated statistical significances in CD. In the subgroup of $\mathrm{AD}$, four genetic models including the recessive model $(\mathrm{OR}=3.03,95 \% \mathrm{CI}=1.34$ to 6.83$)$, dominant model $(\mathrm{OR}=1.41,95 \% \mathrm{CI}=1.13$ to 1.76$)$, allelic model $(\mathrm{OR}=1.29,95 \% \mathrm{CI}=1.04$ to 1.59$)$, and homozygous model $(\mathrm{OR}=3.21,95 \% \mathrm{CI}=1.44$ to 7.18$)$ had been confirmed to be significantly different. Similar results of HSP were found in the recessive model $(\mathrm{OR}=2.60$, $95 \% \mathrm{CI}=1.55$ to 4.37$)$, dominant model $(\mathrm{OR}=1.26$, $95 \% \mathrm{CI}=1.05$ to 1.51$)$, allelic model $(\mathrm{OR}=1.59,95 \%$ $\mathrm{CI}=1.28$ to 1.98$)$, and homozygous model $(\mathrm{OR}=1.88$, $95 \% \mathrm{CI}=1.25$ to 2.82 ). The HSPN subgroup revealed equal numbers of genetic models to HSP, including the recessive model $(\mathrm{OR}=2.88,95 \% \mathrm{CI}=1.72$ to 4.83$)$, dominant model $(\mathrm{OR}=1.65,95 \% \mathrm{CI}=1.33$ to 2.05$)$, allelic model $(\mathrm{OR}=1.27,95 \% \mathrm{CI}=1.06$ to 1.53$)$, and homozygous model $(\mathrm{OR}=2.03,95 \% \mathrm{CI}=1.32$ to 3.12$)$. In $\mathrm{AIH}$ patients, there was no significant association in any genetic model. Therefore, it can be indicated that MIF$173 \mathrm{G} / \mathrm{C}$ may play different roles in the pathogenesis of different autoimmune diseases, based on the stabilities in sensitivity analyses and no publication bias in all included studies.

In conclusion, the present study verified that there was a significant relationship between MIF-173G/C single-nucleotide polymorphism and the susceptibility of autoimmune diseases, whether in Asia, Europe, or North America. MIF-173G/C can be used as a potential therapeutic target in the treatment prescription of autoimmune diseases. However, in different autoimmune diseases, MIF-173G/C fulfilled various functions. So welldesigned studies with larger sample size are needed to explore the specific mechanism in which MIF-173G/C affects the pathogenesis of different autoimmune diseases. 


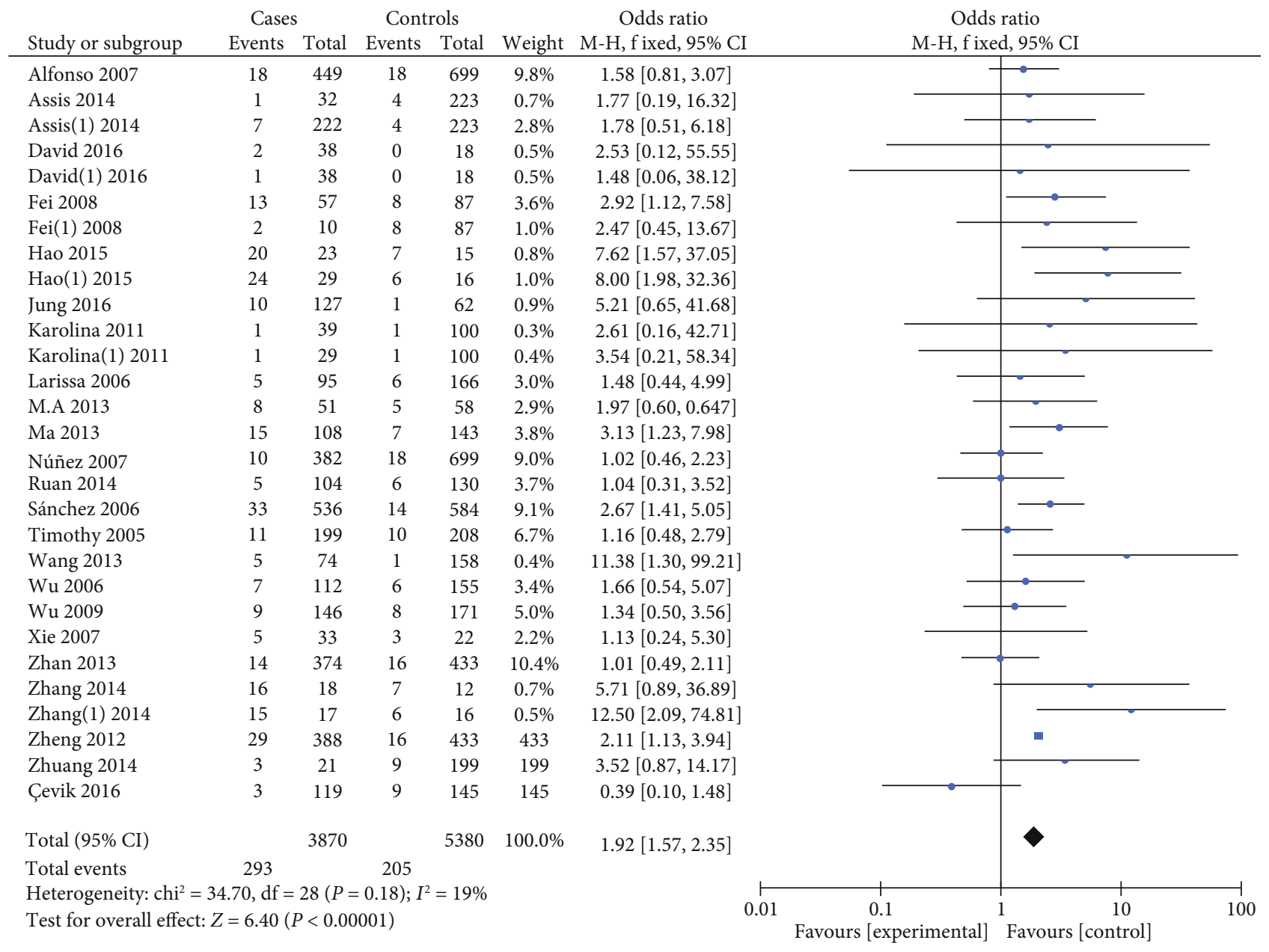

FIGURe 6: Association between MIF-173G/C gene polymorphism and autoimmune diseases in homozygous model (CC/GG).

TABLE 3: The summary of the results from different comparative genetic models in different areas.

\begin{tabular}{|c|c|c|c|c|c|c|c|c|c|c|c|}
\hline Areas & Genetic models & $I^{2}(\%)$ & $P_{\mathrm{I}}$ & $\begin{array}{l}\text { Effects } \\
\text { model }\end{array}$ & OR (95\% CI) & $Z$ & $P_{\mathrm{z}}$ & $\begin{array}{c}\text { Egger's regression } \\
\text { analysis }\end{array}$ & $P_{\mathrm{E}}$ & $\begin{array}{c}\text { Begg's regression } \\
\text { analysis }\end{array}$ & $P_{\mathrm{B}}$ \\
\hline \multirow{5}{*}{ Asia } & $\mathrm{C} / \mathrm{G}$ & 49.5 & 0.01 & FIX & $1.40(1.28,1.54)$ & 7.28 & 0.01 & -0.22 & 0.79 & -0.87 & 0.38 \\
\hline & $\mathrm{CC} / \mathrm{GG}$ & 0 & 0.84 & FIX & $1.91(1.55,2.38)$ & 6.03 & 0.01 & 1.79 & 0.15 & 1.10 & 0.27 \\
\hline & GC/GG & 0 & 0.57 & FIX & $1.29(1.15,1.44)$ & 4.39 & 0.01 & -1.10 & 0.03 & -1.78 & 0.08 \\
\hline & $\mathrm{CC}+\mathrm{GC} / \mathrm{GG}$ & 14.1 & 0.29 & FIX & $1.38(1.23,1.53)$ & 5.76 & 0.01 & 0.34 & 0.39 & 0.42 & 0.68 \\
\hline & $\mathrm{CC} / \mathrm{GC}+\mathrm{GG}$ & 26.3 & 0.15 & FIX & $2.32(1.79,3.00)$ & 6.42 & 0.01 & 1.46 & 0.29 & 0.87 & 0.38 \\
\hline \multirow{5}{*}{ Europe } & $\mathrm{C} / \mathrm{G}$ & 27.8 & 0.20 & FIX & $1.21(1.06,1.37)$ & 2.87 & 0.01 & 1.95 & 0.30 & 0.42 & 0.68 \\
\hline & $\mathrm{CC} / \mathrm{GG}$ & 5.3 & 0.39 & FIX & $1.56(1.10,2.21)$ & 2.52 & 0.01 & 0.16 & 0.92 & 0 & 1 \\
\hline & GC/GG & 11.3 & 0.34 & FIX & $1.51(0.99,1.35)$ & 1.81 & 0.70 & 1.52 & 0.36 & 0 & 1 \\
\hline & $\mathrm{CC}+\mathrm{GC} / \mathrm{GG}$ & 14.9 & 0.31 & FIX & $1.20(1.03,1.39)$ & 2.36 & 0.01 & -0.02 & 0.81 & 1.04 & 0.30 \\
\hline & $\mathrm{CC} / \mathrm{GC}+\mathrm{GG}$ & 10 & 0.35 & FIX & $1.58(1.09,2.29)$ & 2.43 & 0.02 & -0.22 & 0.89 & -0.21 & 0.84 \\
\hline \multirow{5}{*}{ North America } & $\mathrm{C} / \mathrm{G}$ & 0 & 0.72 & FIX & $1.28(1.10,1.48)$ & 3.17 & 0.01 & -8.79 & 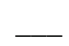 & -1.00 & 0.32 \\
\hline & $\mathrm{CC} / \mathrm{GG}$ & 0 & 0.40 & FIX & $1.30(0.80,2.12)$ & 1.05 & 0.29 & -8.79 & 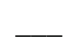 & -1.00 & 0.32 \\
\hline & GC/GG & 0 & 0.59 & FIX & $1.38(1.16,1.65)$ & 3.64 & 0.01 & 134.28 & - & 1.00 & 0.32 \\
\hline & $\mathrm{CC}+\mathrm{GC} / \mathrm{GG}$ & 0 & 0.77 & FIX & $1.38(1.16,1.63)$ & 3.71 & 0.01 & 0.08 & _ & 1.00 & 0.32 \\
\hline & $\mathrm{CC} / \mathrm{GC}+\mathrm{GG}$ & 0 & 0.37 & FIX & $1.21(0.73,2.00)$ & 0.75 & 0.45 & -0.87 & _ & -1.00 & 0.32 \\
\hline
\end{tabular}


TABLE 4: The summary of the results from different comparative genetic models in different diseases.

\begin{tabular}{|c|c|c|c|c|c|c|c|c|c|c|c|}
\hline Diseases & Genetic models & $I^{2}(\%)$ & $P_{\mathrm{I}}$ & $\begin{array}{l}\text { Effects } \\
\text { model }\end{array}$ & OR $(95 \% \mathrm{CI})$ & $Z$ & $P_{\mathrm{z}}$ & $\begin{array}{c}\text { Egger's regression } \\
\text { analysis }\end{array}$ & $P_{\mathrm{E}}$ & $\begin{array}{c}\text { Begg's regression } \\
\text { analysis }\end{array}$ & $P_{\mathrm{B}}$ \\
\hline \multirow{5}{*}{ RA } & $\mathrm{C} / \mathrm{G}$ & 0 & 0.51 & FIX & $1.16(1.03,1.31)$ & 2.37 & 0.02 & -1.76 & 0.18 & -0.98 & 0.33 \\
\hline & $\mathrm{CC} / \mathrm{GG}$ & 0 & 0.96 & FIX & $1.43(0.95,2.14)$ & 1.72 & 0.09 & -0.40 & 0.75 & -0.49 & 0.62 \\
\hline & GC/GG & 13.5 & 0.33 & FIX & $1.12(0.99,1.28)$ & 1.76 & 0.08 & -1.87 & 0.14 & -1.47 & 0.14 \\
\hline & $\mathrm{CC}+\mathrm{GC} / \mathrm{GG}$ & 11.9 & 0.34 & FIX & $1.20(1.01,1.43)$ & 2.12 & 0.03 & -2.03 & 0.13 & -0.98 & 0.33 \\
\hline & $\mathrm{CC} / \mathrm{GC}+\mathrm{GG}$ & 0 & 0.98 & FIX & $1.38(0.92,2.07)$ & 1.53 & 0.13 & -0.06 & 0.95 & 0 & 1.00 \\
\hline \multirow{5}{*}{ UC } & $\mathrm{C} / \mathrm{G}$ & 32 & 0.23 & FIX & $1.22(1.00,1.47)$ & 1.99 & 0.05 & 5.19 & 0.21 & 1.57 & 0.12 \\
\hline & CC/GG & 0 & 0.47 & FIX & $1.86(0.98,3.50)$ & 1.91 & 0.06 & -0.49 & 0.89 & -0.52 & 0.60 \\
\hline & GC/GG & 51.6 & 0.13 & FIX & $1.11(0.91,1.38)$ & 1.50 & 0.14 & 4.85 & 0.44 & 0.52 & 0.60 \\
\hline & $\mathrm{CC}+\mathrm{GC} / \mathrm{GG}$ & 29.3 & 0,24 & FIX & $1.15(0.96,1.38)$ & 1.50 & 0.14 & 5.74 & 0.10 & 1.57 & 0.12 \\
\hline & $\mathrm{CC} / \mathrm{GC}+\mathrm{GG}$ & 0 & 0.39 & FIX & $1.93(1.01,3.01)$ & 1.99 & 0.05 & -1.23 & 0.77 & -0.52 & 0.60 \\
\hline \multirow{5}{*}{$\mathrm{CD}$} & $\mathrm{C} / \mathrm{G}$ & 0 & 0.58 & FIX & $1.23(1.04,1.47)$ & 2.40 & 0.02 & 1.14 & 0.53 & 1.57 & 0.12 \\
\hline & $\mathrm{CC} / \mathrm{GG}$ & 0 & 0.49 & FIX & $1.22(0.64,2.33)$ & 0.60 & 0.55 & 2.66 & 0.13 & 1.57 & 0.12 \\
\hline & GC/GG & 0 & 0.54 & FIX & $1.32(1.11,1.57)$ & 3.14 & 0.01 & -0.19 & 0.92 & -0.52 & 0.60 \\
\hline & $\mathrm{CC}+\mathrm{GC} / \mathrm{GG}$ & 0 & 0.68 & FIX & $1.30(1.10,1.52)$ & 3.09 & 0.01 & 0.24 & 0.90 & 0.52 & 0.60 \\
\hline & $\mathrm{CC} / \mathrm{GC}+\mathrm{GG}$ & 0 & 0.42 & FIX & $1.14(0.59,2.18)$ & 0.38 & 0.7 & 2.53 & 0.24 & 0.52 & 0.60 \\
\hline \multirow{5}{*}{$\mathrm{AIH}$} & $\mathrm{C} / \mathrm{G}$ & 0 & 0.40 & FIX & $1.03(0.73,1.45)$ & 0.17 & 0.86 & -6.57 & 0.03 & -1.57 & 0.12 \\
\hline & $\mathrm{CC} / \mathrm{GG}$ & 0 & 0.97 & FIX & $1.86(0.40,8.75)$ & 0.79 & 0.43 & 0.31 & 0.87 & -0.52 & 0.60 \\
\hline & GC/GG & 39.8 & 0.19 & FIX & $0.93(0.67,1.29)$ & 0.43 & 0.67 & -10.62 & 0.04 & -1.57 & 0.12 \\
\hline & $\mathrm{CC}+\mathrm{GC} / \mathrm{GG}$ & 27.4 & 0.25 & FIX & $0.98(0.71,1.33)$ & 0.16 & 0.87 & -9.52 & 0.01 & -1.57 & 0.12 \\
\hline & $\mathrm{CC} / \mathrm{GC}+\mathrm{GG}$ & 0 & 0.95 & FIX & $1.98(0.42,9.32)$ & 0.87 & 0.39 & 1.39 & 0.61 & 0.52 & 0.60 \\
\hline \multirow{5}{*}{$\mathrm{AD}$} & $\mathrm{C} / \mathrm{G}$ & 0 & 0.52 & FIX & $1.41(1.13,1.76)$ & 3.03 & 0.01 & 2.37 & & 1.00 & 0.32 \\
\hline & $\mathrm{CC} / \mathrm{GG}$ & 0 & 0.62 & FIX & $3.21(1.44,7.18)$ & 2.84 & 0.01 & 3.42 & & 1.00 & 0.32 \\
\hline & GC/GG & 0 & 0.60 & FIX & $1.21(0.96,1.52)$ & 1.6 & 0.11 & 1.67 & & 1.00 & 0.32 \\
\hline & $\mathrm{CC}+\mathrm{GC} / \mathrm{GG}$ & 0 & 0.67 & FIX & $1.29(1.04,1.59)$ & 2.38 & 0.02 & 2.02 & & 1.00 & 0.32 \\
\hline & $\mathrm{CC} / \mathrm{GC}+\mathrm{GG}$ & 0 & 0.65 & FIX & $3.03(1.34,6.83)$ & 2.67 & 0.01 & 3.02 & & 1.00 & 0.32 \\
\hline \multirow{5}{*}{ AP } & $\mathrm{C} / \mathrm{G}$ & 0 & 0.39 & FIX & $1.59(1.28,1.98)$ & .12 & 0.01 & 18.13 & & 1.00 & 0.32 \\
\hline & $\mathrm{CC} / \mathrm{GG}$ & 9.7 & 0.29 & FIX & $1.88(1.25,2.82)$ & 3.03 & 0.01 & 10.79 & & 1.00 & 0.32 \\
\hline & GC/GG & 0 & 0.46 & FIX & $1.22(0.89,1.68)$ & 1.21 & 0.23 & 82.99 & & 1.00 & 0.32 \\
\hline & $\mathrm{CC}+\mathrm{GC} / \mathrm{GG}$ & 0 & 0.57 & FIX & $1.26(1.05,1.51)$ & 2.40 & 0.02 & 8.90 & & 1.00 & 0.32 \\
\hline & $\mathrm{CC} / \mathrm{GC}+\mathrm{GG}$ & 0 & 0.61 & FIX & $2.60(1.55,4.37)$ & 3.60 & 0.01 & 15.55 & & 1.00 & 0.32 \\
\hline \multirow{5}{*}{ HSPN } & $\mathrm{C} / \mathrm{G}$ & 0 & 0.78 & FIX & $1.65(1.33,2.05)$ & 4.54 & 0.01 & 8.39 & - & 1.00 & 0.32 \\
\hline & $\mathrm{CC} / \mathrm{GG}$ & 0 & 0.70 & FIX & $2.03(1.32,3.12)$ & 3.21 & 0.01 & 7.45 & - & 1.00 & 0.32 \\
\hline & GC/GG & 0 & 0.87 & FIX & $1.15(0.82,1.61)$ & 0.81 & 0.42 & 34.18 & - & 1.00 & 0.32 \\
\hline & $\mathrm{CC}+\mathrm{GC} / \mathrm{GG}$ & 0 & 0.97 & FIX & $1.27(1.06,1.53)$ & 2.63 & 0.01 & 4.63 & $\longrightarrow$ & 1.00 & 0.32 \\
\hline & $\mathrm{CC} / \mathrm{GC}+\mathrm{GG}$ & 0 & 0.88 & FIX & $2.88(1.72,4.83)$ & 4.02 & 0.01 & 7.69 & 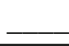 & 1.00 & 0.32 \\
\hline
\end{tabular}

\section{Abbreviations}

MIF: $\quad$ Macrophage migration inhibitory factor

AID: $\quad$ Autoimmune diseases

ORs: $\quad$ Odds ratio

95\% CIs: $\quad 95 \%$ of confidence intervals

RA: $\quad$ Rheumatoid arthritis

UC: $\quad$ Ulcerative colitis

CD: $\quad$ Crohn's disease

AD: $\quad$ Atopic dermatitis

HSP: Henoch-Schonlein purpura
HSPN: Henoch-Schonlein purpura nephritis

AIH: $\quad$ Autoimmune hepatitis

GD: $\quad$ Graves' disease

CNKI: China National Knowledge Infrastructure

PRIMSA: $\quad$ Preferred Reporting Items for Systematic Review and Meta-analysis statement

HWE: Hardy-Weinberg equilibrium

NOS: $\quad$ Newcastle-Ottawa Scale

PCR-RFLP: Polymerase Chain Reaction-Restriction Fragment Length Polymorphism

SLE: $\quad$ Systemic lupus erythematosus. 


\section{Data Availability}

The data used to support the findings of this study are available from the corresponding author upon request.

\section{Conflicts of Interest}

The authors declare no conflict of interest.

\section{Authors' Contributions}

Xiangrong Du and Ruixia Li contributed equally to this work.

\section{Acknowledgments}

The work was supported by the Natural Science Foundation of Shandong Province (ZR2013HM049), the Key Research and Development Program of Shandong Province (2016GSF201021), the Science and Technology Program of Higher Education of Shandong Province (J16LL01), the Science and Technology Development Project of Medicine and Health of Shandong Province (2015WS0485), and the Scientific Research Starting fund of Binzhou Medical University (BY2010KYQD04).

\section{References}

[1] T. Z. el-Adly, S. Kamal, H. Selim, and S. Botros, "Association of macrophage migration inhibitory factor promoter polymorphism -173G/C with susceptibility to childhood asthma," European Journal of Immunology, vol. 3, no. 3, pp. 268-272, 2016.

[2] D. N. Assis, L. Leng, X. du et al., "The role of macrophage migration inhibitory factor in autoimmune liver disease," Hepatology, vol. 59, no. 2, pp. 580-591, 2014.

[3] M. Y. Areeshi, R. K. Mandal, S. A. Dar et al., "MIF-173 G > C (rs755622) Gene Polymorphism Modulates Tuberculosis Risk: Evidence from a Meta-analysis and Trial Sequential Analysis," Scientific Reports, vol. 7, no. 1, article 17003, 2017.

[4] J. Bloom, S. Sun, and Y. al-Abed, "MIF, a controversial cytokine: a review of structural features, challenges, and opportunities for drug development," Expert Opinion on Therapeutic Targets, vol. 20, no. 12, pp. 1463-1475, 2016.

[5] B. Karakaya, C. H. M. van Moorsel, A. H. M. van der Helmvan Mil et al., "Macrophage migration inhibitory factor (MIF) -173 polymorphism is associated with clinical erythema nodosum in Löfgren's syndrome," Cytokine, vol. 69, no. 2, pp. 272-276, 2014.

[6] J. Dambacher, T. Staudinger, J. Seiderer et al., "Macrophage migration inhibitory factor (MIF) $-173 \mathrm{G} / \mathrm{C}$ promoter polymorphism influences upper gastrointestinal tract involvement and disease activity in patients with Crohn's disease," Inflammatory Bowel Diseases, vol. 13, no. 1, pp. 71-82, 2007.

[7] F. Sun, X. Zhang, W. Weng et al., "The association between the migration inhibitory factor $-173 \mathrm{G} / \mathrm{C}$ polymorphism and cancer risk: a meta-analysis," Onco Targets and Therapy, vol. 8, pp. 601-613, 2015.

[8] X. Tong, Z. Yan, Q. Zhou et al., "Association between the MIF$173 G / C$ polymorphism and serum MIF levels with pulmonary tuberculosis: a meta-analysis," Scientific Reports, vol. 7, no. 1, p. $234,2017$.
[9] Z. X. Shan, Y. H. Fu, X. Y. Yu et al., "Association of the polymorphism of macrophage migration inhibitory factor gene with coronary heart disease in Chinese population," Chinese Journal of Medical Genetics, vol. 23, no. 5, pp. 548-550, 2006.

[10] A. Arakelyan, L. Nersisyan, D. Poghosyan et al., "Autoimmunity and autoinflammation: a systems view on signaling pathway dysregulation profiles," PLoS One, vol. 12, no. 11, article e0187572, 2017.

[11] K. H. Costenbader, S. Gay, M. E. Alarcón-Riquelme, L. Iaccarino, and A. Doria, "Genes, epigenetic regulation and environmental factors: which is the most relevant in developing autoimmune diseases?," Autoimmunity Reviews, vol. 11, no. 8, pp. 604-609, 2012.

[12] Q. Xie, S. C. Wang, G. Bian, F. L. Zhan, J. K. Xie, and J. Li, "Association of MIF-173G/C and MBL2 codon 54 gene polymorphisms with rheumatoid arthritis: a meta-analysis," Human Immunology, vol. 73, no. 9, pp. 966-971, 2012.

[13] Y. H. Liu, C. C. Chen, C. M. Yang, Y. J. Chen, and F. J. Tsai, "Dual effect of a polymorphism in the macrophage migration inhibitory factor gene is associated with new-onset Graves disease in a Taiwanese Chinese population," PLoS One, vol. 9, no. 3, article e92849, 2014.

[14] B. Y. Fei, H. X. Lv, J. M. Yang, and Z. Y. Ye, “Association of MIF-173 gene polymorphism with inflammatory bowel disease in Chinese Han population," Cytokine, vol. 41, no. 1, pp. 44-47, 2008.

[15] E. Leoncini, G. Carioli, C. la Vecchia, S. Boccia, and G. Rindi, "Risk factors for neuroendocrine neoplasms: a systematic review and meta- analysis," Annals of Oncology, vol. 27, no. 1 , pp. 68-81, 2016.

[16] L. de la Fontaine, M. J. Schwarz, M. Riedel et al., "Investigating disease susceptibility and the negative correlation of schizophrenia and rheumatoid arthritis focusing on MIF and CD14 gene polymorphisms," Psychiatry Research, vol. 144, no. 1, pp. 39-47, 2006.

[17] M. A. Llamas-Covarrubias, Y. Valle, R. Bucala et al., "Macrophage migration inhibitory factor (MIF): genetic evidence for participation in early onset and early stage rheumatoid arthritis," Cytokine, vol. 61, no. 3, pp. 759-765, 2013.

[18] A. Martínez, G. Orozco, J. Varadé et al., "Macrophage migration inhibitory factor gene: influence on rheumatoid arthritis susceptibility," Human Immunology, vol. 68, no. 9, pp. 744747, 2007.

[19] T. R. D. J. Radstake, F. C. G. J. Sweep, P. Welsing et al., "Correlation of rheumatoid arthritis severity with the genetic functional variants and circulating levels of macrophage migration inhibitory factor," Arthritis and Rheumatism, vol. 52, no. 10, pp. 3020-3029, 2005.

[20] C. M. Xie, The MIF detection and analysis of single nucleotide polymorphism of MIF gene in rheumatoid arthritis, Master Dissertation of Chongqing Medical University, 2007.

[21] C. Núñez, B. Rueda, A. Martínez et al., "Involvement of macrophage migration inhibitory factor gene in celiac disease susceptibility," Genes and Immunity, vol. 8, no. 2, pp. 168-170, 2007.

[22] K. Przybyłowska, J. Mrowicki, A. Sygut et al., "Contribution of the -173 G/C polymorphism of macrophage migration inhibitory factor gene to the risk of inflammatory bowel diseases," Polski Przeglad Chirurgiczny, vol. 83, no. 2, pp. 76-80, 2011.

[23] G. C. Ruan, H. Yang, and J. M. Qian, The study of the association of MDR1 and MIF gene polymorphism with ulcerative 
colitis in Chinese Han population, Doctoral Dissertation of Beijing Union Medical College, 2014.

[24] D. N. Assis, H. Takahashi, L. Leng, M. Zeniya, J. L. Boyer, and R. Bucala, "A macrophage migration inhibitory factor polymorphism is associated with autoimmune hepatitis severity in US and Japanese patients," Digestive Diseases and Sciences, vol. 61, no. 12, pp. 3506-3512, 2016.

[25] J. S. Kim, J. Choi, H. J. Hahn, Y. B. Lee, D. S. Yu, and J. W. Kim, "Association of macrophage migration inhibitory factor polymorphisms with total plasma IgE levels in patients with atopic dermatitis in Korea," PLoS One, vol. 11, no. 9, article e0162477, 2016.

[26] L. Ma, H. B. Xue, X. H. Guan, R. Q. Qi, and Y. B. Liu, "Macrophage migration inhibitory factor promoter $173 \mathrm{G} / \mathrm{C}$ polymorphism is associated with atopic dermatitis risk," International Journal of Dermatology, vol. 53, no. 1 , pp. e75-e77, 2014.

[27] L. Hao, Y. H. Zhang, and P. Li, “Comparison of polymorphism of MIF-173 gene locus with Henoch-Scholein purpura nephritis of children between the Han nationality and Moggol nationality," Chinese Journal of Nephrology, vol. 31, no. 1, pp. 58-59, 2015.

[28] Y. H. Zhang and P. Li, "Comparison of polymorphism of MIF173 gene locus with Henoch-Scholein purpura of children between the Han nationality and Moggol nationality," International Journal Of Pediatrics, vol. 42, no. 5, pp. 559-562, 2015.

[29] Ç. Gürel, A. İnanır, A. Nursal, A. Tekcan, A. Rüstemoğlu, and S. Yigit, "Evaluation of MIF -173 G/C polymorphism in Turkish patients with ankylosing spondylitis," Balkan Medical Journal, vol. 33, no. 6, pp. 614-619, 2016.

[30] Z. Y. Zhuang, B. Liu, R. M. Chuai, X. U. Longqiang, L. I. Changgui, and S. Liu, "Relationship between macrophage migration inhibitory factor-173G/C polymorphism and susceptibility to gout in Chinese male population," Chinese Journal of Rheumatology, vol. 17, no. 10, pp. 692-695, 2013.

[31] J. Wu, F. Chen, X. Zhang et al., “Association of MIF promoter polymorphisms with psoriasis in a Han population in Northeastern China," Journal of Dermatological Science, vol. 53, no. 3, pp. 212-215, 2009.

[32] E. Sánchez, L. M. Gómez, M. A. Lopez-Nevot et al., "Evidence of association of macrophage migration inhibitory factor gene polymorphisms with systemic lupus erythematosus," Genes and Immunity, vol. 7, no. 5, pp. 433-436, 2006.

[33] C. Zhang, S. Liu, S. Hou et al., "MIFGene polymorphisms confer susceptibility to vogt-koyanagi-harada syndrome in a Han Chinese population," Investigative Ophthalmology \& Visual Science, vol. 54, no. 12, pp. 7734-7738, 2013.

[34] F. F. Wang, X. F. Huang, N. Shen et al., "A genetic role for macrophage migration inhibitory factor (MIF) in adult-onset still's disease," Arthritis Research and Therapy, vol. 15, no. 3, article R65, 2013.

[35] X. Zheng, D. Wang, S. Hou et al., “Association of macrophage migration inhibitory factor gene polymorphisms with Behçet's disease in a Han Chinese population," Ophthalmology, vol. 119, no. 12, pp. 2514-2518, 2012.

[36] S. P. Wu, L. Leng, Z. Feng et al., "Macrophage migration inhibitory factor promoter polymorphisms and the clinical expression of scleroderma," Arthritis and Rheumatism, vol. 54, no. 11, pp. 3661-3669, 2006.

[37] H. Fan, W. Kao, Y. H. Yang et al., "Macrophage migration inhibitory factor inhibits the antiinflammatory effects of gluco- corticoids via glucocorticoid-induced leucine zipper," Arthritis and Rheumatology, vol. 66, no. 8, pp. 2059-2070, 2014.

[38] Y. Shen, S. Guo, T. Yang et al., "The -173 G/C polymorphism of the MIF gene and inflammatory bowel disease risk: a metaanalysis," International Journal of Molecular Sciences, vol. 14, no. 6, pp. 11392-11401, 2013.

[39] T. E. Meawed, M. A. Mansour, S. A. Mansour, M. L. Mohamed, E. M. Ibrahim, and A. M. Ali, "Functional and prognostic relevance of - $173 \mathrm{G} / \mathrm{C}$ gene polymorphism of macrophage migration inhibitory factor in sepsis patients in Egyptian intensive care units," Eastern Mediterranean Health Journal, vol. 21, no. 10, pp. 762-769, 2015.

[40] A. Onat, G. Can, N. Çoban et al., "Lipoprotein (a) level and MIF gene variant predict incident metabolic syndrome and mortality," Journal of Investigative Medicine, vol. 64, no. 2, pp. 392-399, 2016.

[41] A. Savva, M. C. Brouwer, T. Roger et al., "Functional polymorphisms of macrophage migration inhibitory factor as predictors of morbidity and mortality of pneumococcal meningitis," Proceedings of the National Academy of Sciences of the United States of America, vol. 113, no. 13, pp. 35973602, 2016.

[42] G. Benedek, R. Meza-Romero, K. Jordan et al., "MIF and DDT are potential disease severity modifiers in male MS subjects," Proceedings of the National Academy of Sciences of the United States of America, vol. 114, no. 40, pp. E8421-E8429, 2017.

[43] A. Sreih, R. Ezzeddine, L. Leng et al., "Dual effect of the macrophage migration inhibitory factor gene on the development and severity of human systemic lupus erythematosus," Arthritis and Rheumatism, vol. 63, no. 12, pp. 3942-3951, 2011.

[44] R. Liu, N. Xu, X. Wang et al., "Influence of MIF, CD40, and CD226 polymorphisms on risk of rheumatoid arthritis," Molecular Biology Reports, vol. 39, no. 6, pp. 6915-6922, 2012. 